\title{
A PRODUÇÃO DA SUBJETIVIDADE NO CONTEXTO INSTITUCIONAL DE UM SEMINÁRIO CATÓLICO
}

\author{
THE PRODUCTION OF THE SUBJECTIVITY ON THE \\ INSTITUTIONAL CONTEXT OF A CATHOLIC SEMINARY
}

Sílvio José BENELLI ${ }^{1}$ Abílio da COSTA-ROSA ${ }^{2}$

\begin{abstract}
RESUMO
Esta pesquisa visa estudar a produção da subjetividade no contexto institucional de um Seminário Católico. Este estabelecimento funciona em regime de internato no qual atualmente 70 seminaristas estudam Filosofia durante 3 anos, numa etapa preparatória para o sacerdócio. Pesquisamos o funcionamento da vida institucional através da observação participante e utilizamos entrevistas semi-estruturadas para entender como o seminarista experiencia sua vida. Os resultados preliminares indicam que a vida no contexto institucional do Seminário produz diversas modalizações da subjetividade nos seminaristas internados no estabelecimento: há uma perda considerável de autonomia pessoal, da liberdade de ir e vir, agir e decidir, originando comportamentos de dependência excessiva, de resistência à mudança, de conversão ao papel proposto, de rivalidade fraterna. A contradição detectada entre o aparelho repressivo e o discurso participativo parece produzir nos indivíduos características marcadas pela clivagem e pela recusa.
\end{abstract}

Palavras-chave: psicologia e religião, produção da subjetividade, análise institucional, seminário católico, instituições totais, internato escolar, observação participante.

\section{ABSTRACT}

This reseach aims to study the production of the subjectivity on the institutional context of a Catholic Seminary. This is a boarding school in

(1) Aluno do Curso de Pós-Graduação em Psicologia - Faculdade de Ciências e Letras, UNESP, Assis, SP. Av. Tarumã, 577. Centro. Tarumã, SP, CEP 19820-000 Fone: (18) 3329-1234. E-mail: sjbewelli@yahoo.com.br (2) Professor Assistente Doutor junto ao Departamento de Psicologia Clínica e do Curso de Pós-Graduação em Psicologia - Faculdade de Ciências e Letras, UNESP, Assis, SP.

Este artigo foi produzido a partir de uma pesquisa realizada em Nível de Iniciação Científica, com financiamento da FAPESP. Atualmente, está sendo desenvolvida em Nível de Mestrado por Sílvio José Benelli, sob orientação do Prof. Dr. Abílio da Costa-Rosa. 


\begin{abstract}
which 70 seminarists study Philosophy for 3 years, as a preparatory activity to priesthood. The way of being of the institutional life was researched through the participating observation and half-structured interviews were carried on in order to make out how the seminarist experiences his life on the institutional context. The preliminary outcome shows that we can understand the seminary as a total institution, a place comprising residence, work, study, background, sociability and entertainment, where lots of people living alike but apart from the well-off society lead a reclusive life and formally administrated. Life in the institutional context of the Seminary brings about several facets of subjectivity to the seminarist. There is a deep loss on the personal autonomy, freedom of going out and coming back, acting and deciding as well, causing a behavior of excessive dependence, resistence of changing, conversion to the proposed role and fratenal rivalry. The contradiction found between the repressive apparatus and the participating speech seems to cause the people characteristics set by fragmentation and refusal.
\end{abstract}

Key words: psychology and religion, production on subjectivity, institutional analysis, catholic seminary, total institutions, boarding school, participating observation.

Neste artigo pretendemos relatar os resultados de um estudo sobre um Seminário Católico no qual nos propusemos a analisar a referida instituição como dispositivo de modelagem e produção de subjetividade.

Tomamos como pano de fundo teórico um conjunto de formulações sobre as instituições, porém com destaque maior para o referencial de Goffman (1987) para análise das Instituições Totais. Nossa meta era dupla; por um lado, conhecer numa primeira aproximação esse Seminário Católico quanto a seus aspectos instituídos e eventualmente instituintes, recortando-o como Formação Social, portanto dando destaque à sua dimensão molar: suas práticas e discursos constituídos, as forças presentes em sua visibilidade mais imediata. Por outro lado, tínhamos o objetivo de retomar as idéias principais de Goffman sobre o assunto, para experimentar sua operatividade analítica no contato com nosso objeto de estudo e com nossos objetivos específicos de analisá-lo como dispositivo de produção de subjetividade. Pretendíamos ver até que ponto as hipóteses de Goffman sobre as Instituições Totais como dispositivos centrados em práticas de mortificação do eu podiam ou não mostrar-se capazes de nos fornecer conhecimentos relevantes sobre o Seminário Católico; e em que pontos tais hipóteses podem mostrar-se limitadas.

Relacionando esse Seminário com o Convento, tínhamos em mente a hipótese sobre sua natureza, de certo modo, particular em relação aos Manicômios e às Prisões. Porém, como nossa meta principal era o estudo da modelagem subjetiva e outros possíveis processos de subjetivação em ação nesse Seminário, para a formação de sacerdotes, pensamos ser uma boa estratégia partir da sua análise como Instituição Total.

Analisar esse Seminário em paralelo com as Instituições Totais, seguindo a teoria de Goffman (1987), não significa que o identifiquemos integralmente com todas as características do modelo estabelecido por Goffman, haja vista que o próprio autor afirma que nem todos os traços se encontram de modo igual nos diversos estabelecimentos totais. Trata-se de uma modalidade de funcionamento que detectamos nesse 
Seminário, mas com sua especificidade própria. Queremos destacar alguns aspectos que têm equivalência e impacto em termos de produção de subjetividade.

Há diferenças, entre as Instituições Totais, quanto ao modo de recrutamento: o espectro vai da coerção legal ao ingresso espontâneo. Um indivíduo, quando ingressa num Seminário, o faz espontaneamente, sem coerções legais nem restrições, mas mediante seu esforço ativo, movido inclusive por um chamado vocacional. Estar nesse Seminário pesquisado, de acordo com os dados, significa uma importante ocasião de promoção social e cultural para a maior parte dos seminaristas internados. Essa é uma diferença importante entre o Seminário e outras Instituições Totais mais opressivas, como os Manicômios e as Prisões. Embora não apresente o rigor explícito destas, constatamos nesse Seminário o funcionamento de mecanismos mais ou menos sutis, visando à modelagem subjetiva. É preciso ressaltar que, embora o indivíduo seja livre para ingressar no Seminário, uma vez constituído membro dessa comunidade, ele passa a estar sujeito a toda uma série de pressões e coerções sociais informais, implícitas nas obrigações que adquire, já que estas se convertem no caminho para chegar às recompensas da formatura ou da ordenação sacerdotal.

Como a entrada no Seminário acontece a partir da vocação, em muitos casos, esta parece ser sentida como um chamado inexorável, como um chamado inarredável ao qual não se pode deixar de responder. Ao seu modo, com sua especificidade, esse Seminário possui elementos importantes que nos permitem entendê-lo como uma Instituição Total, a partir dos dados que coletamos.

Pesquisamos como se organiza a vida dos seminaristas no contexto social do estabelecimento no qual vivem durante a realização de sua formação filosófica. Os seminaristas vivem em comunidade, moram, estudam e se divertem juntos e no mesmo espaço físico. Têm uma vida de internados, com maior ou menor contato com a realidade externa. Seu tempo é programado de modo uniforme pela equipe dirigente (os formadores), aos quais devem obediência. Os formadores são os representantes indicados pelos bispos para administrarem o Seminário. Em sua formação, durante os anos de estudos em que vive no Seminário, o indivíduo torna-se seminarista e passa por uma modelagem institucional de sua subjetividade, que culmina com sua ordenação como padre; ocasião em que, geralmente, deixa o Seminário.

\section{INSTITUIÇÕES MODELADORAS E PRODUTORAS DE SUBJETIVIDADE}

As práticas sociais, quaisquer que sejam, produzem subjetividade e subjetivação, produzem também dispositivos de subjetivação. Na perspectiva em que estamos trabalhando, consideramos a subjetividade não como um dado estático e natural, mas como algo que se constitui em processos. Um exemplo é a teorização de Freud, cartografando como é que se constitui a subjetividade humana, com a sua variabilidade e plasticidade pulsional, dependente de uma série de variáveis. A cultura da Formação Capitalista Liberal também modela e produz uma variação de subjetividade que culmina na categoria de indivíduo auto-suficiente, autoconsciente, senhor de si mesmo, o sujeito centrado no eu. Assim como em termos mais amplos, podemos ver a categoria indivíduo como a produção específica de uma modalidade de subjetividade. É nestes termos que, a partir de Goffman (1987), estamos trabalhando com a hipótese de que o modo de funcionamento das Instituições Totais operam como produtoras de uma certa modalidade da subjetividade.

A produção de subjetividade remete fundamentalmente ao plano micropolítico, microfísico das relações instituintes e instituídas da formação no contexto do Seminário Católico. Na perspectiva do contexto 
institucional, as relações formativas (pedagógicas, terapêuticas, educativas) entre padres formadores e seminaristas não se configuram como relações estáticas entre pólos constituídos, mas apresentam-se em permanente constituição e ordenação - plenas de vicissitudes - em constante transformação dos lugares e posições no interior das relações, numa pulverização dos lugares instituídos e instituintes.

Desse modo, não podemos conceber práticas e/ou sujeitos autônomos, pois toda prática é efetivada por relações nas quais se configuram sujeitos. Essa é a principal condição para que as instituições existam concretamente. A solidez institucional residiria nos vínculos entre os sujeitos que as fazem cotidianamente, vínculos invisíveis, microfísicos. Portanto, as relações instituintes e instituídas do processo formativo no contexto institucional do Seminário Católico poderiam ser mapeadas a partir das forças e dos poderes moleculares que as permeiam.

A relação entre a equipe de formadores e os seminaristas, na diversidade de relações que se estabelecem no contexto institucional desse Seminário Católico, relações de formação, que possui matizes pedagógicos e terapêuticos, revela-se como a mais recorrente e legitimada, soberana entre outras. Essas relações formativas, no cruzamento de relações distintas mas interdependentes, podem ser consideradas como o núcleo central que caracteriza um certo contrato educativo e formativo informal que institui as relações no Seminário. Pensamos que ela é um dispositivo privilegiado de constituição desse Seminário enquanto agência de produção de subjetividade.

Dentre as práticas sociais de modelagem da subjetividade, a internação em Instituições Totais (Goffman, 1975, 1987) tem sido historicamente uma estratégia extremamente freqüente. Estas instituições foram e continuam sendo utilizadas como agências produtoras de subjetividade, modelando-a de acordo com o contexto institucional, ao promoverem relações peculiares entre dirigentes e internados no conjunto das práticas institucionais (Foucault,1984,1999a,1999b; Guirado,1986,1987). Esse lapso de tempo no qual o indivíduo vive internado pode deixar marcas profundas na sua subjetividade, o que faz com que a questão se configure enquanto um tema de estudo apropriado em si mesmo.

São poucos os estudos que levam em conta o conhecimento da produção da subjetividade no contexto institucional em geral (Guirado, 1986, 1987; Albuquerque, 1980; Ferraz e Ferraz, 1994) e também especificamente em instituições religiosas formadoras. Constatamos que são raros os trabalhos que estudam estruturação do sujeito e o contexto cultural institucional no qual ele se insere. A maioria dos estudos tratam do hospital geral, do hospital psiquiátrico e da prisão (Levinson \& Gallagher, 1971; Castel, 1978; Goffman, 1987; Foucault, 1999a, 1999b). O convento, o mosteiro, o Seminário e o colégio interno parecem ter sido menos pesquisados em sua especificidade.

De acordo com Goffman (1987), um estudo profundo do funcionamento institucional e dos diversos fenômenos que se produzem nesse espaço social específico pode proporcionar indícios valiosos quanto aos procedimentos utilizados na formação de pessoas. Seria possível entender como essas instituições produzem a subjetividade daqueles que as compõem, tanto a dos internados quanto a dos dirigentes.

O Seminário Católico, sendo uma instituição dedicada à formação, tem características peculiares em relação aos demais estabelecimentos do gênero. Seu funcionamento prevê que seus internados se tornarão padres, passando de internado/seminarista/formando a dirigente/padre/formador. O Seminário produz padres, que são agentes formados e que se tornam, por sua vez, agentes formadores, embora essencialmente produza padres para os quadros da Igreja Católica e que serão, de certo modo, líderes de destaque 
junto a setores numerosos da população. Acreditamos que seu processo formativo tem uma incidência direta no tipo de prática social desenvolvida por esse agente. Para entender melhor esse ator social que tem sua relevância no meio social, é que nos debruçamos sobre a instituição Seminário, estudando-a e procurando produzir um conhecimento a seu respeito.

Socialização é um conceito sociológico que designa um processo global de preparação de um indivíduo para o desempenho de determinado papel social. Este processo de aprendizado e treinamento necessário ao desempenho de papéis socialmente estabelecidos se realiza na convivência social. Nesse sentido, podemos considerar o Seminário como uma agência de socialização, um estabelecimento que socializa determinados indivíduos com o objetivo de prepará-los para desempenhar o papel social de sacerdote.

Para o psicólogo, o conceito de socialização designa também as trocas que se realizam entre o indivíduo e a sociedade, geralmente através dos grupos e pessoas significativas. Apesar de visualizar os dados sociológicos envolvidos neste processo, para o psicólogo importa acentuar os aspectos psíquicos da interação.

Desse modo, podemos entender a socialização - no plano psíquico - como um processo básico de constituição do eu que possibilita ao indivíduo introjetar e assimilar padrões, comportamentos, ideais e valores característicos do grupo a que pertence ou no qual está inserido. Esse processo não se circunscreve a apenas um período da vida: os indivíduos passam por diversas experiências socializadoras ao longo da vida e sob a influência das mais diversas instituições e estabelecimentos; a cada transição, tem como tarefa reavaliar e reorganizar sua personalidade.

Nesta pesquisa sobre a produção da subjetividade no contexto institucional de um Seminário Católico, estamos recuperando os estudos de Goffman (1987) para a leitura das instituições totalitárias. Consideramos que Goffman realiza uma modalidade de análise institucional que pode ser situada no plano do estrato, no nível macro ou molar dos fenômenos que ocorrem nos estabelecimentos fechados. Sua concepção explícita de poder é a de um poder essencialmente modelador, poder instaurado, repressivo e mutilador do eu em sua missão (res)socializadora. Isso parece ser o que Goffman apresenta inicialmente numa primeira leitura.

O que nos propusemos fazer neste trabalho foi uma análise fundada no dispositivo analítico das Instituições Totais, porém quisemos voltar a Goffman (1987) depois de ler algumas das contribuições de Foucault e da Análise Institucional relativas à produção da subjetividade no contexto institucional. Uma leitura mais atenta de Goffman então nos permitiu encontrar nele também uma dimensão produtiva do poder: há uma microssociologia dos estabelecimentos totalitários que explicita toda uma tecnologia de poder altamente criativa. Certamente podemos identificar opressores e oprimidos, caracterizados pela equipe dirigente e pelo grupo dos internados, os primeiros modelam e os segundos são objetos de procedimentos modeladores. Mas Goffman descreve minuciosamente as reações de (contra)controle que os dois grupos antagônicos exercem um sobre o outro: há modelagem e resistências; vigilância permanente e recíproca; há lutas e conflitos nos planos macro e microfísicos. Goffman mapeia estratégias ostensivas de ataque e reações que se esboçam às vezes sutis, outras claramente defensivas ou sabotadoras. Mostra-nos como o grupo dos internados se defende dos esforços modeladores através de diversas táticas adaptativas e utilizando-se dos próprios recursos institucionais para construir um mundo pessoal contrário aos objetivos oficiais do estabelecimento. Desse modo o Seminário Católico, visto por esse prisma, é muito mais produtor do que mortificador da subjetividade, 
suas práticas se mostram predominantemente mais modeladoras do que mortificadoras.

\section{ESTRATÉGIAS E TÁTICAS DE MODELAGEM SUBJETIVA NAS INSTITUIÇÕES TOTAIS SEGUNDO GOFFMAN}

A equipe dirigente de um estabelecimento totalitário organiza burocraticamente a vida no contexto institucional. De um modo geral, estes estabelecimentos funcionam como um depósito de internados, mas apresentam-se ao público como organizações racionais, planejadas de modo consciente como máquinas eficientes para atingir determinados objetivos e capazes de cumprir certas finalidades oficialmente declaradas. Um de seus objetivos oficiais mais amplos e freqüentes é a (re)educação dos internados na direção de algum padrão ideal. São verdadeiras máquinas de sobrecodificação da subjetividade. A contradição entre os objetivos oficiais confessados e aquilo que o estabelecimento realmente produz constitui-se no contexto básico do trabalho cotidiano da equipe dirigente (Goffman, 1987, pág.70).

O trabalho da equipe dirigente se reduz à administração, gerenciamento e controle de pessoas. Como material de trabalho, as pessoas podem também ser reduzidas às características de objetos inanimados, podendo ser vistas apenas em seus aspectos físicos. $O$ indivíduo pode ser etiquetado como um produto, numerado, encaixado numa nosografia, inscrito e descrito em relatórios e prontuários que dizem o que foi feito por ele, com ele e quais foram os responsáveis. Seu registro de caso vai crescendo à medida que vão sendo acrescentadas notas e pareceres da equipe dirigente.

Os estabelecimentos totais funcionam mais ou menos como um Estado e sua equipe dirigente tem que enfrentar problemas de um modo parecido aos que têm os governantes de estados (Goffman, 1987, pág. 72), deparandose com dilemas clássicos, como por exemplo: conflitos entre meios e fins, manutenção de padrões humanitários versus eficiência institucional, esforços para evitar fugas, esconder decisões quanto ao destino dos internados, distância versus afeição pelos internados e outras dificuldades específicas no trabalho com pessoas.

A rotina da equipe dirigente é estruturada em torno das exigências especiais do trabalho com pessoas e é realizada num clima moral específico: a equipe dirigente enfrenta a hostilidade e exigências dos internados e precisa apresentar a eles a perspectiva racional defendida pelo estabelecimento (Goffman, 1987, pág. 77).

O esquema de interpretação quanto à natureza presumida do que é um ser humano de um estabelecimento total entra em funcionamento automático quando da admissão do internado. A admissão é tomada como uma prova concreta de que é com um indivíduo assim que o estabelecimento trabalha. Esse é o centro de um meio básico de controle social.

Os internados, quando podem, fazem pedidos, e a equipe dirigente apresenta justificações ideológicas para a imposição de restrições. Assim, a equipe dirigente controla os internados e defende a instituição em nome de seus objetivos confessados: os castigos e privilégios que distribui são apresentados numa linguagem que expressa essas metas oficiais (Goffman, 1987, pág. 78).

Cada perspectiva institucional contém uma moralidade pessoal. Os internados devem ser conduzidos à auto-orientação controlável e a conduta desejável e a indesejável precisam ser definidas como decorrentes da vontade pessoal deles, definidas como algo que se pode controlar.

Assim, a equipe dirigente tende a criar uma teoria sobre a natureza humana, que racionaliza sua atividade, estabelece e mantém a distância social com o internado, dá uma 
interpretação estereotipada dele e justifica o tratamento que lhe é imposto. Essa teoria geralmente abrange as possibilidades adequadas e irregulares de conduta do internado, o valor institucional de privilégios e castigos e também a diferença essencial entre a equipe dirigente e o grupo dos internados.

A teoria sobre a natureza humana desenvolvida no ambiente institucional totalitário costuma considerar o ser humano como um ser fraco. Para lidar com ele, é preciso lançar mão de soluções intermediárias, mostrar consideração, utilizar medidas de proteção. Pode ser necessário utilizar prêmios e incentivos que levem o indivíduo a colaborar quando seus objetivos não coincidem com os da instituição. Os participantes também podem ser estimulados a colaborar, induzidos por ameaças e castigos: as sanções negativas podem incluir uma redução nos prêmios ou nos níveis usuais de bem-estar. O medo do castigo pode ser adequado para impedir que $o$ indivíduo realize ou deixe de realizar determinados atos. Mas reforços positivos tais como prêmios parecem necessários para que se obtenha um esforço prolongado, contínuo e pessoal. A noção de que os indivíduos respondem a castigos ou prêmios como meio para produzir a resposta esperada exige suposições diferentes relativas ao que seja a natureza humana. Portanto, a organização total não se limita a utilizar a atividade de seus participantes, mas ela também delineia os padrões oficiais adequados de bem-estar, valores conjuntos, incentivos e castigos. A própria ação da equipe dirigente ou da administração exprime a concepção que ela tem dos indivíduos sobre os quais atua. Boa parte dos conflitos entre os dois grupos antagônicos diz respeito à concepção da natureza e papel impostos aos internados e às diferentes reações deles a esse caráter presumido pelos dirigentes.

A estrutura funcional do estabelecimento cria suposições de papéis e identidade sociais. Quando o indivíduo participa de determinada atividade com o ânimo e disposição que se espera dele, está aceitando implicitamente que é um determinado tipo de pessoa que vive num mundo específico. Todo estabelecimento, além de incluir uma disciplina de atividade, produz também uma constituição subjetiva específica; ele modela o ser do indivíduo, impondo-Ihe um determinado caráter e um ambiente específico onde deve manifestá-lo. Esse ser prescrito, essas suposições a respeito do eu costumam ser sistematicamente enfrentadas pelos participantes internados através de diferentes estratégias de adaptação e, sobretudo, por meio dos ajustamentos secundários. Agir e ser, nesse caso, estão longe de ser equivalentes (Goffman, 1987, pág. 158).

A tarefa da equipe dirigente é receber os internados e aplicar-Ihes uma série de procedimentos que visam ao seu controle e modelagem subjetiva. Goffman (1987, pág. 24) os denomina de processos de mortificação do eu, são padronizados e incluem os seguintes aspectos: enclaustramento/sequestração do indivíduo; processos de admissão que criam uma pasta pessoal que é continuamente alimentada com relatórios sobre o desempenho do internado; testes de obediência para conseguir a cooperação inicial do novato; despojamento dos bens, emprego e carreira; exposições contaminadoras físicas, sociais e psicológicas; o "circuito", interligando todas as esferas da vida do internado no contexto institucional, utilizando um comportamento qualquer como índice do estado geral da sua condição pessoal; o sistema de privilégios, através do qual manipula arbitrariamente algumas necessidades e satisfações do indivíduo, utilizando-as como prêmios concedidos em troca de obediência. Essa seria a tecnologia de modelagem, instrumentos implementados para modificar e transformar as pessoas.

Mas Goffman (1987, pág. 159) detecta que os internados não se submetem tão facilmente aos procedimentos (res)socializadores. Estes 
criam ajustamentos secundários, práticas que não desafiam diretamente a equipe dirigente, mas Ihes permitem obter satisfações proibidas ou conseguir, por meios proibidos, as satisfações permitidas. Os internados "conhecem as manhas" para usufruir uma certa autonomia pessoal, reagindo às pressões ostensivas da equipe dirigente. Poderíamos dizer que os internados inventam as "manhas" e criam também uma gíria institucional própria para se comunicarem em segredo. Criam também controles sociais informais utilizando a cooptação ou a coerção pela força e violência para evitar que delatores os entreguem à equipe dirigente. Através do processo de confraternização, o grupo dos internados se une, desenvolve apoio mútuo e uma cumplicidade como resistência a um sistema que os forçou à intimidade numa única comunidade igualitária de destino. A gozação coletiva expressa o repúdio geral e vingança contra a autoridade sentida como inimiga. A solidariedade produz uma infinidade de grupos primários no estabelecimento: panelinhas, facções, ligações sexuais mais ou menos estáveis, a formação de pares, através dos quais dois internados passam a ser reconhecidos como "amigos" ou "casal" pelos demais companheiros. Nos casos em que não se pode confiar nos companheiros, que representariam uma ameaça potencial permanente, o internado experimentaria anomia e solidão, apesar de conviver num grande grupo (Goffman, 1987, pág. 58).

A equipe dirigente (re)age contra os esforços (re)ativos do grupo dos internados que se une na busca de estratégias para neutralizar os efeitos modeladores do estabelecimento totalitário. Pode também combater a solidariedade, porque a união dos internados pode ser vista como um fator que facilita atividades combinadas proibidas. Pode reconhecer tacitamente ou proibir os relacionamentos de "casais", considerando-os incestuosos, impedindo que a dupla crie um mundo próprio no estabelecimento.
Por seu lado, o grupo dos internados também cria uma série de estratégias adaptativas às condições ambientais do estabelecimento: pode afastar-se da realidade como uma recusa em participar; com sua intransigência pode desafiar intencionalmente a equipe dirigente, negando-se de modo visível a colaborar; pode adotar a vida no estabelecimento como se fosse seu lar, através da colonização; o internado pode aceitar a interpretação oficial da equipe dirigente e procurar representar o papel do internado perfeito, disciplinado, moralista, sempre à disposição, através da estratégia da conversão; finalmente, pode "se virar", utilizar um "jogo de cintura", numa combinação oportunista de diversas estratégias que visam obter uma possibilidade máxima de evitar sofrimentos físicos ou psicológicos.

As estratégias adaptativas dos internados colocam a equipe dirigente diante de alguns paradoxos. A colonização, que seria o objetivo oculto máximo da instituição, dado o nível elevado de cooperação do internado, é paradoxalmente vista como um problema para a instituição: a equipe dirigente pode ficar perturbada, ao perceber que as possibilidades positivas da situação estão sendo mal empregadas. Os próprios colonizados podem sentir-se obrigados a negar sua satisfação, mesmo que seja apenas por razões de solidariedade com seus companheiros. Podem ainda sabotar espontaneamente sua saída, criando problemas próximo da data fixada para sair do estabelecimento, prolongando sua estadia. Os esforços da equipe dirigente para melhorar as condições de vida na instituição têm de enfrentar a possibilidade de aumentar a atração e a própria colonização.

Além disso, a vida no contexto institucional ainda produz alguns efeitos específicos no grupo dos internados. Efeitos que não estão previstos nos objetivos oficiais do estabelecimento e que acrescentam novos problemas para a equipe dirigente. Costumam surgir alguns tipos e níveis de preocupação 
pessoais características no grupo dos internados.

O internado é colocado numa posição social inferiorizada, comparativamente à que ocupava no mundo exterior, sob a ação do processo de mortificação e de despojamento ao qual é submetido. Isso cria nele uma sensação de fracasso pessoal e de desgraça constante. Como reação a esse sentimento, o internado costuma criar uma estória pessoal que funciona como um conto triste, num estilo de lamentação e defesa, elaborando sua versão para explicar sua situação de inferioridade atual. Ele conta sua história aos companheiros, em tom de autopiedade. Os colegas tendem a ouvi-lo com condescendência e a equipe dirigente costuma desmenti-lo.

Outra característica é que, entre os internados de muitos estabelecimentos totais, existe uma forte sensação de que o tempo de internação é inútil, perdido, roubado de sua vida, tempo que precisa ser apagado, cumprido, preenchido ou arrastado de algum modo. Durante sua estada obrigatória, o internado costuma sentir que esteve completamente exilado da vida. Isso indica que internações excessivamente prolongadas têm um efeito proporcionalmente desmoralizador. Condições precárias de vida, perda de contatos sociais, impossibilidade de adquirir dinheiro, de formações de relações conjugais e ausência de certidão de estudos realizados são outros elementos que explicam essa sensação de tempo perdido na instituição.

Daí advém o alto valor das atividades de distração, sejam individuais ou coletivas, nesses estabelecimentos: jogos ao ar livre, bailes, festas, banda de música, coral, teatro, aulas, ateliês de arte, trabalhos manuais, televisão, filmes, jogos de cartas, homossexualidade, álcool, drogas que possibilitam "viagens". Essas e outras atividades de entretenimento ajudam o indivíduo a relaxar, aliviando um pouco a tensão produzida pelos ataques constantes à sua pessoa. Esse aspecto também parece ser conseqüência de uma certa regressão e infantilização que a vida no contexto institucional geram no internado.

Podem surgir também alguns problemas no processo de reinserção do internado na vida cotidiana do mundo externo. Quando o internado é enviado de volta à sociedade mais ampla, ele pode experimentar algumas dificuldades, tais como a angústia, o estigma (Goffman, 1975) e a desaculturação.

Para os que estão internados, a vida no mundo externo costuma ser seu sonho mais precioso e seu desejo se chama liberdade. Mas, paradoxalmente, a proximidade da saída do estabelecimento cria angústia e muitos podem provocar a continuidade da internação para evitar o problema. O temor é criado pela questão: "Será que vou conseguir me virar no mundo?" A sociedade externa apresenta uma face desafiadora, diante de um indivíduo altamente desmoralizado. Muitos internados deixam aberta a possibilidade de regressar ao estabelecimento.

A angústia no tempo da reinserção parece ser produzida principalmente pela desaculturação, que pode ser entendida como a perda ou impossibilidade de adquirir os hábitos atualmente exigidos na sociedade. A recepção do ex-internado pode ser fria e o estigma adquirido pode dificultar-Ihe a tarefa de arrumar um emprego ou um lugar para viver. Geralmente, a libertação costuma ocorrer quando o indivíduo já domina sua vida no ambiente institucional, que se the tornou conhecido e ao qual ele se adaptou de algum modo, conseguindo alguns privilégios dos quais aprendeu, dolorosamente, o alto valor. Assim, o ex-internado pode descobrir que ser livre significa passar do topo de um pequeno mundo já familiar para o ponto mais baixo de uma sociedade ampla, provavelmente fria, indiferente ou hostil.

Podemos notar que há todo um jogo de forças, uma luta, um estado de guerra entre a equipe dirigente e o grupo dos internados. $\mathrm{O}$ próprio dispositivo institucional produz efeitos paradoxais para ambos os grupos no seu 
funcionamento dinâmico. A equipe dirigente vigia seus internados e também é vigiada pelos internados no cumprimento de suas funções. A sociedade e o mundo exterior também vigiam o funcionamento do estabelecimento. Os "problemas de gorvernante" enfrentados pela equipe dirigente revelam que ela sofre influências e tem que administrar as ações e reações geradas pelo grupo dos internados. Há lutas e conflitos também no seio do grupo dos internados: impossível não notar a agressividade e sexualidade que ali fervilham, na surdina.

Goffman apresenta os cerimoniais institucionais como outros espaços nos quais essas lutas internas podem se apresentar de modos diversos, podendo servir também como momentos de trégua nos combates, uma pausa estratégica para aliviar a pressão excessiva, descansar e recuperar as forças.

Trata-se de práticas institucionalizadas que exprimem solidariedade, unidade e compromisso conjunto de toda a instituição, produzindo-se uma maior aproximação dos dois grupos, possibilitando que ambos tenham uma visão mais positiva um do outro e se identifiquem com a situação alheia. Nestes cerimoniais institucionais, há uma liberação das formalidades, dos papéis estereotipados e da usual distância entre a equipe dirigente e os internados, a participação pode ser relativamente voluntária. Vamos enumerar os principais elementos nos quais se exprimem esses cerimoniais: jornal ou revista periódica do estabelecimento; a festa anual do aniversário do estabelecimento; o teatro institucional; a exibição institucional (a abertura dos portões uma vez por ano, para que os parentes dos internados e o público em geral visitem o estabelecimento); a sala de visitas, apresentações de caridade e os esportes internos.
As cerimônias institucionais tendem a ocorrer dentro de uma certa periodicidade espaçada, despertam alguma excitação social, todos os grupos do estabelecimento participam, independentemente de posto ou posição, mas recebem um lugar que exprime sua posição. Uma sociedade perigosamente dividida entre internados e equipe dirigente pode ser unida através de tais cerimônias. Geralmente a equipe dirigente se queixa de tédio por ter que participar de tais cerimônias e o faz por causa da noblesse oblige ou por temor dos superiores. Os internados participam por causa do conforto e da suspensão das restrições, para ficar bem diante da equipe dirigente e talvez conseguir a liberdade mais depressa.

Um estabelecimento total precisa de cerimônias coletivas porque é algo mais do que apenas uma organização formal. No entanto, essas cerimônias podem ser "forçadas" e insípidas, porque a instituição é algo menos do que uma comunidade.

De acordo com Goffman (1987), embora os estabelecimentos totais tenham como objetivo a reforma e a reabilitação, através das quais o indivíduo recuperaria os mecanismos auto-reguladores supostamente perdidos, e pretendam que ele mantenha de modo espontâneo os padrões nos quais foi reeducado e ressocializado no estabelecimento, isso não costuma ocorrer exatamente assim.

Na prática, raramente se consegue essa mudança. As alterações permanentes que realmente costumam ocorrer não são as desejadas pela equipe dirigente. Exceto no caso de algumas instituições religiosas, os processos de despojamento e os de reorganização não parecem produzir um efeito duradouro. O indivíduo se defendeu da "reforma" imposta através dos ajustamentos secundários, nos quais se habituou a costumes contrários à instituição, além de se valer da estratégia de "dançar conforme a música". 


\section{A PESQUISA DE CAMPO NUM SEMINÁRIO CATÓLICO}

\section{SUJEITOS}

Realizamos essa pesquisa num Seminário Católico, numa cidade do Estado de São Paulo. Para tanto, obtivemos autorização do reitor do estabelecimento. Este Seminário recebe candidatos ao sacerdócio de várias dioceses que se reuniram para sua criação. Tomamos como sujeito propriamente dito o estabelecimento como um todo, que foi observado em seu funcionamento. De modo mais especifico, investigamos também a concepção dos internados (seminaristas) sobre sua própria vida, no contexto institucional.

Não se trata de um estudo de caso, mas escolhemos este Seminário especificamente por que ele nos parece um representante bastante adequado em sua singularidade, de alguns aspectos disciplinares importantes que caracterizam as Instituições Totais, manifestos no seu cotidiano. Acreditamos que não se trate de um caso ímpar, ele nos parece realmente representativo da categoria Seminário Maior Católico que desejamos compreender. Estamos interessados nos matizes de Instituição Total presentes neste Seminário, mas acreditamos, por hipótese, que ele não se distingue de muitos outros em sua essência institucional, pois a estruturação característica desses estabelecimentos totais parece funcionar de modo autônomo.

Este Seminário é constituído por grandes construções: dois pavilhões com térreo e primeiro andar, divididos em celas individuais (os quartos dos seminaristas), que abrigam ainda banheiros coletivos, uma biblioteca, sala de informática, sala de leituras e um anfiteatro; há um outro bloco que abriga cozinha, despensa, refeitório e lavanderia. Há também um conjunto denominado prédio escolar, que inclui salas de aula, de televisão, secretaria, sala de visitas e alguns quartos para os seminaristas no primeiro andar. Finalmente, temos uma grande capela, um campo de futebol gramado, uma quadra de esportes e as garagens dos veículos.

Atualmente, o quadro do pessoal existente no estabelecimento é o seguinte: 70 seminaristas, 03 padres formadores (reitor, vice-reitor, diretor espiritual), 04 cozinheiras, 02 lavadeiras, 01 secretária, 01 bibliotecária, 01 diretor de estudos e 20 professores. Dos professores, 04 são padres e 06 são leigos do sexo feminino, os demais são leigos do sexo masculino. Os padres formadores têm entre 35 e 45 anos. Já os seminaristas oscilam entre 18 e 45 anos, sendo que todos já concluíram obrigatoriamente o segundo grau.

\section{INSTRUMENTOS}

\section{OBSERVAÇÃO PARTICIPANTE}

Para realizar essa pesquisa, utilizamos a técnica da observação participante (AlvesMazzotti, 1998; Triviños, 1987), qualitativa, rigorosa, sistemática e vivencial. A observação participante foi do tipo não-estruturada, na qual os fenômenos a serem observados não são predeterminados, eles foram observados e relatados da forma como aconteceram, visando descrever e compreender o que estava ocorrendo na situação dada. A técnica da observação participante envolveu três fases: (a) aproximação da instituição e estabelecimento de vínculos com seus membros; (b) realização da observação no contexto dos sujeitos para a coleta de dados; e (c) registro posterior dos fenômenos, comportamentos, ações, diálogos e acontecimentos observados. Realizamos 20 visitas de observação participante.

Os dados foram sistematizados em categorias analíticas (Goffman, 1987) com base nos relatórios das observações. Estabelecemos quatro grandes categorias: (a) o mundo do internado no Seminário, em que apresentamos dados relativos ao ingresso 
do jovem vocacionado na instituição, as vicissitudes pelas quais desenvolve sua "carreira moral" no Seminário, os processos de mortificação aos quais é submetido (reclusão, arquivo pessoal), exposições contaminadoras físicas, sociais e psicológicas, o circuito, a tiranização, sistema de privilégios, ajustamentos secundários, estratégias adaptativas; (b) o mundo dos formadores no Seminário, em que tratamos dos itens: os seminaristas como elementos humanos do trabalho da equipe de formadores, problemas de "governantes" no gerenciamento do Seminário, os representantes da perspectiva oficial da Igreja, considerações sobre a natureza humana e capacidade moral dos formadores a respeito dos formandos, reinterpretação institucional do trabalho, a dimensão acadêmica do Seminário: o curso filosófico; (c) os cerimoniais institucionais no Seminário: jornal do Seminário, teatro institucional, sala de visitas, a semana de estudos teológico-filosóficos, assembléias de comunicação, convivências institucionais, celebrações litúrgicas, festa de aniversário do Seminário; (d) outros aspectos relevantes do contexto institucional do Seminário: diferenças intragrupais, conflitos ideológicos, reunião de seminaristas por grupos diocesanos, manhãs de formação espiritual, modo de recrutamento dos seminaristas, graus de permeabilidade do estabelecimento, destino social dos seminaristas egressos, processos de desligamento do seminarista do Seminário.

\section{ENTREVISTAS SEMI-ESTRUTURADAS}

Numa segunda etapa desta pesquisa, examinamos o seminarista em si mesmo, pois ele não é apenas um objeto dos esforços da equipe formadora e das pressões institucionais, mas é também um indivíduo cujas formas de adaptação às oportunidades e exigências da vida no internato são complexas. Para tanto, utilizamos entrevistas semi-estruturadas (Bleger, 1980; Triviños, 1987).
Realizamos um total de nove entrevistas com três seminaristas de cada ano do curso de Filosofia, que vivem internados no estabelecimento pesquisado, que foram gravadas e depois transcritas. Abordamos os seguintes temas: história vocacional, ingresso e experiência no Seminário Menor, o que é ser seminarista, como seriam o Seminário e o seminarista ideais, o caminho para a formação sacerdotal que o estabelecimento oferece, problemas que o seminarista enfrenta no Seminário, como é a vida comunitária, aspectos positivos e negativos da vida do seminarista, visão sobre a equipe de formadores, sobre os colegas e a respeito do curso de filosofia, parecer sobre os diversos instrumentos formativos, estado atual da vocação sacerdotal, diante da experiência institucional no Seminário.

$\mathrm{Na}$ análise das entrevistas, utilizamos três figuras metodológicas para a organização do material coletado, buscando discriminar os principais temas que constituem o discurso apresentado pelos seminaristas, relativo tanto à sua própria percepção quanto à experiência formativa que vivem no Seminário: expressõeschave, idéia central e o Discurso do Sujeito Coletivo (Lefèvre, 2000).

Deste modo, resgatamos o conteúdo das representações individuais, construindo com elas o Discurso do Sujeito Coletivo, pois as pessoas são, ao mesmo tempo, estruturadoras das representações sociais e estruturadas por elas. No contexto institucional, elas produzem e são produzidas pelo seu meio ambiente ideológico, no qual interagem dialeticamente, na medida em que há uma interpenetração, uma porosidade constitutiva entre o contexto e os indivíduos. De uma perspectiva institucional, podemos dizer que são sujeitos que se fundam no interior das práticas, sujeitos ao mesmo tempo constituídos e constituintes do cotidiano institucional. Quando um sujeito fala, seu discurso pode ser tomado enquanto uma representação do lugar institucional que ocupa: seu pensamento pode incluir também 
aquilo que outros indivíduos socialmente equivalentes verbalizam por ele.

\section{RESULTADOS}

Temos abundante material das visitas de observação participante que se encontra à disposição do leitor, mas que não podem ser apresentados num artigo como este. Vamos apresentar alguns fragmentos das entrevistas, em itálico.

O seminarista definido por ele mesmo:

Ser seminarista é fazer o exercício de uma futura situação de vida. O seminarista é um "mini-padre", porque você já tem que começar a ter atitudes de padre. Suas atitudes e tudo o mais devem estar já refletindo essa vida do sacerdócio. É um estudante de filosofia, que almeja no futuro ser padre, mas que não tem nada certo nem garantido, porque é difícil. Desde que a gente entra já tem o compromisso de viver o celibato. Esse não é o maior problema de todos. O mais difícil é o conflito da vida em comunidade. Existe a exigência de você sair da sua casa, entrar num lugar para morar com gente que não conhece, que são diferentes, provêm de outras realidades. A gente precisa se anular muito para viver em comunidade no Seminário.

Os seminaristas podem ser classificados em vários tipos: os romanos, que são aqueles que gostam de se destacar, aparecer, são soberbos e cheios de si; os da Teologia da Libertação são mais radicais. Os seminaristas da Teologia da Libertação combatem os romanos. As duas facções são radicais nos seus posicionamentos. Também há a categoria dos neutros. Tem um outro grupo que é difícil classificar. São aqueles que entram no Seminário para esconder alguma coisa ou para praticar certas coisas sem que os outros percebam. Trata-se de um grupo que pode ser classificado como homossexuais. Uma parte dos seminaristas sofre com isso, sofrem por ser seminaristas. Se o rapaz quer mesmo ser padre, deve estudar, enfrenta problemas de família, problemas que se acumulam e dificultam o processo formativo.

O seminarista se percebe como um indivíduo institucionalizado que precisa adotar uma conduta clerical, o "mini-padre", enquadrado dentro de uma comunidade que se revela altamente conflitante, dividida em diferentes grupos com características ideológicas antagônicas: os conservadores (romanos), os progressistas (libertadores), os "neutros" e os "homossexuais". Além desses aspectos, existe a dimensão acadêmica (estudante de filosofia), compondo a definição multifacetada do seminarista.

Os diferentes problemas enfrentados pelos seminaristas advêm das diversas dimensões que constituem sua vida no contexto institucional:

a) acadêmicos: Um seminarista precisa de tempo para organizar sua vida e poder estudar. Os que haviam parado de estudar têm dificuldade com o ritmo de estudos do Seminário;

b) relativos à condição de formando do seminarista: Também precisa de paciência porque a maioria dos seminaristas são ansiosos e querem tudo imediatamente: querem a atenção do povo, querem ser necessários e procurados pelas pessoas. Sua utilidade pastoral lhes dá a identidade de seminarista;

c) de ordem material: Para o seminarista a pior coisa do mundo é o aspecto financeiro: ele vive todo o processo formativo sem dinheiro, sempre dependendo da generosidade da paróquia de origem ou de onde faz pastoral. 
Quando precisamos comprar alguma coisa, a família às vezes não tem condição de ajudar, a paróquia dá uma contribuição, mas nem sempre é suficiente, então a gente abre mão de muita coisa. A maioria dos seminaristas não têm dinheiro e vivem "duros". Alguns poucos não têm problema financeiros, pois eles têm dinheiro ou então têm quem banque suas necessidades. Por você estar num Seminário diocesano, está sem dinheiro, porque eles te oferecem casa, comida, roupa lavada e seu colégio; o resto, você tem que dar conta, tem que se virar;

d) na vida comunitária: A convivência pode ser problemática: lidar com o diferente, o outro, é complicado, principalmente quando você vive junto das seis da manhã à meia-noite. Depois de novo, todo dia. Há muitos conflitos entre os grupos, nas panelinhas. Não presenciei nenhum momento que tivesse levado a falar sobre essas coisas. Todo mundo sabe desses problemas mas faz de conta que não existem. Os seminaristas estão vendo, mas não querem ver, procuram apenas fazer a sua parte;

e) no âmbito sexual: Há os que não se resolveram sexualmente e vem se esconder aqui; perdemos a liberdade de ser nós mesmos. As questões humanoafetivas que você traz, que tem que resolver da sua vida, aí elas ficam muito evidentes, sobretudo os casos de homossexualidade. O maior problema é que você não tem com quem contar, não tem ajuda. Se você falar de seus problemas afetivos com os formadores, de tendências para o homossexualismo, está no olho da rua. Vão dizer que procure outro lugar, porque você precisa rever algumas coisas, se tem esse tipo de problemas, o Seminário não é um lugar adequado para você. Então a gente vive num clima de tensão, tem que estar se policiando, se vigiando, com cuidado para não dar bandeira. Viver num lugar desses é difícil;

f) o seminarista experimenta "crises": Tem as crises. Essas crises que todo mundo fala. Não sei se eu passo isso, ficar meio melancólico, meio triste. Quando um colega vê a gente triste, já pergunta: o que você tem? Não vai sair do Seminário não, né?

g) ele também sofre e sente falta da vida fora do estabelecimento: Às vezes tem sofrimento na vida do seminarista. Bate a solidão, saudade da daquela vida lá fora. Tenho a impressão de que as pessoas são mais felizes lá fora do que aqui dentro, não tem aquela pressão de estudar, pressão de rezar e não sei o quê.

h) indica a falta de confiança na relação de formação e um jogo de escondeesconde entre seminaristas e formadores: Falta confiança entre os formadores e os seminaristas, porque isso está muito longe de acontecer. Eles estão numa posição e nós em outra, nos perseguindo o tempo todo, olhando se você está fazendo uma coisa ou não está. Existe uma cumplicidade, um pacto entre os próprios seminaristas, exceto alguns que fogem do esquema. A equipe de formadores não sabe o que acontece entre nós. Entre os formadores, deve ser a mesma coisa, nós não sabemos o que acontece nas reuniões deles;

i) o seminarista vive seus problemas solitariamente: Com relação aos seus problemas, o seminarista costuma vive-los solitariamente. Até mesmo conversar com um padre pode ser arriscado, pois ele pode vir ocupar algum cargo importante na diocese e mandar você embora.

Se o seminarista se vê como um "minipadre", ele ainda está em formação, ainda 
não é um padre e padece das limitações da sua condição de indivíduo institucionalizado: como aluno, tem desafios acadêmicos a enfrentar; já desenvolve "atividades pastorais", mas precisa ser paciente por que ainda não é padre e deve refrear sua ansiedade; a falta de dinheiro é o indicador da real condição de menoridade na qual ele se encontra; a formação exige o modelo de vida em grupo, com diversas manifestações de rivalidade fraterna; é preciso viver sob a autoridade dos formadores numa relação que evita dialogar sobre questões espinhudas, numa tática de avestruz; como ser sexuado, tem que se haver com o desejo polimorfo que o atravessa. O seminarista passa pelas "crises", nas quais experimenta angústia, tristeza, solidão, saudades da vida fora do estabelecimento.

A vida comunitária é caracterizada pelos seminaristas como um campo de batalha. Há toda uma geopolítica estruturando o grande grupo dos seminaristas internados no estabelecimento.

A vida comunitária tem aspectos positivos e negativos. As pessoas mais sociáveis costumam se adaptar melhor, são muito procuradas; já as que são mais tímidas e retraídas costumam ser evitadas e mantidas à distância, o que reforça suas dificuldades de relacionamento e contato social. Pode-se viver solitário e isolado ou então intensamente envolvido na vida comunitária. Também há o problema das fofocas, a vigilância entre os próprios seminaristas, as panelinhas que têm conflitos internos e com outros grupos. Seminaristas do terceiro ano do curso de Filosofia podem discriminar os colegas novatos.

No Seminário, há duas grandes facções ideológicas: os romanos soberbos, que gostam de dogmas, clergiman e batina, e os libertadores radicais. As duas facções são incompatíveis e tendem a classificar os seminaristas à revelia, por seus gostos e inclinações, tratando como pertencendo a esse ou àquele grupo: esse é romano, aquele é libertador, o outro é homossexual, esse é homem, é machão.

Temos uma rotatividade de pessoas, cada ano tem uma turma nova, então você pode ter novos amigos, novas possibilidades, diversos momentos. $O$ grupo que compõe a comunidade está dividido em grupinhos, são pessoas que têm certas afinidades que facilitam amizades. Dentro do grupão, você acaba tendo muitos grupinhos. Todo mundo sabe que existem os grupos. Mas é aquela coisa da guerra fria, a gente sabe que tá todo mundo em guerra, mas ninguém atira, apenas uma vez ou outra, mas é muito difícil. Ao mesmo tempo que se sabe que os grupos estão definidos, a gente finge que não tem grupo nenhum e está tudo bem. Não há espaço para discutir essa questão, que eu me lembre. Temos os diversos grupos, participamos deles e nós e o formadores fingimos que eles não existem, é essa relação estranha.

O grupo dos seminaristas divide-se em facções com orientações ideológicas distintas e opostas. Cada grupo tende a incluir novos membros e excluir outros. A rotatividade de pessoas que chegam e partem todos os anos facilita a flutuação nos relacionamentos. A divisão da comunidade em grupos é algo ao mesmo tempo reconhecido e desconhecido pelos membros do estabelecimento, inclusive pela equipe de formadores.

Envolvidos neste panorama, os seminaristas afirmam que a amizade é algo perigoso no contexto institucional do Seminário:

É difícil ter amigos no Seminário. Você pode confiar em pessoas que se voltam contra você por causa de diferenças ideológicas. Então você pensa que está num lugar onde não se pode ter amigos, porque é difícil confiar nas pessoas que de uma hora para outra se tornam 
inimigas e podem prejudicar você com o que sabem a seu respeito. Aí temos que viver nossos problemas sozinhos, por causa da fofoca. Seu problema percorre toda a comunidade e volta até você distorcido e desproporcional. Ter um relacionamento de amizade com um colega pode causar falatório na comunidade: "fulano e beltrano estão tendo um caso." De repente, uma fofoca como essa é suficiente para que você seja mandado embora.

Chamou a nossa atenção a queixa dos seminaristas relativa ao nível de hostilidade e rivalidade fraterna predominantes no cotidiano da vida institucional. Talvez essa agressividade seja resultado das frustrações e de um alto nível de estresse a que os seminaristas estão expostos no claustro, talvez seja uma reação defensiva contra a excessiva exposição na qual vivem.

Curiosamente, o modo de funcionamento do estabelecimento gera um efeito paradoxal na convivência entre os seminaristas: os objetivos oficiais se propõem uma vida comunitária como contexto formativo por excelência, mas os seminaristas vivem solitários em meio à multidão de companheiros. O padre diocesano se caracteriza normalmente por viver sozinho na paróquia sob sua responsabilidade. Enquanto seminarista inserido no processo formativo institucional, apesar do grande número de companheiros, ele já vive a solidão.

Diante das dificuldades experimentadas no processo formativo vivido no contexto institucional do Seminário, os seminaristas utilizam estratégias adaptativas, sobretudo a "viração":

Como nada se resolve, o seminarista acaba colocando uma máscara: ele faz de conta que ele é um seminarista conforme os formadores querem, cria uma casca e se apresenta assim, mas no fundo ele é outra pessoa. Ele dança conforme a música. Há seminaristas que querem o poder, a glória e o status de padre e por isso agüentam tudo, comem o pão que o diabo amassou, mas tudo passa. Aíquando chegarem a ser padre, não querem nem olhar para a cara de seminaristas, nem para o Seminário, porque foi traumatizante, maçante para eles.

Quando você tenta lutar, discutir os conflitos, conversar com as pessoas, dar atenção, apoio, alguém já vê isso como homossexualidade e a pessoa se fecha novamente. É por isso que ninguém se ajuda aqui: solidariedade parece coisa de "boiola", daí fica cada um na sua, dança conforme a música que o reitor toca, se ele não ama, também não preciso amar, basta fingir.

O que a gente vê são as notas das provas saindo. Os bispos querem notas. Os relatórios do reitor também saem, indicando o comportamento dos seminaristas. A gente não conhece o conteúdo do relatório, então isso pode nos prejudicar, por isso, é preciso se comportar direitinho, ao menos na fachada. Se der muito na cara, o seminarista se ferra, isso vai no relatório dele para o bispo e ele é logo mandado embora.

Tendo seus conflitos e necessidades tacitamente ignorados e/ou desconhecidos, submetidos a instrumentos formativos opressivos, os seminaristas lançam mão da dissimulação como uma estratégia adaptativa, numa manifestação de resistência passiva ao controle a que estão sujeitos.

Os seminaristas também observam aspectos positivos na sua vida no Seminário:

Os aspectos positivos na vida de um seminarista são: contato com muitas pessoas de diferentes lugares; possibilidades de viajar e conhecer lugares históricos, participar de eventos culturais importantes; a dimensão 
acadêmica é um aspecto que faz crescer muito; obter uma formação universitária; fazer teatro e experimentar o sucesso e uma certa realização pessoal, estar se reunindo com as pessoas num cantinho para conversar, embaixo da árvore, ou então estar no quarto de um conversando, as amizades que se criam, os poucos momentos de confraternização; a "pastoral" que está sendo uma escola do que vamos abraçar no futuro. A vida do seminarista também tem suas vantagens: tem desconto no cinema, na farmácia, tem um certo status social e essas coisas não são sofrimentos. Mas no seu íntimo, ele tem muitos conflitos que o fazem sofrer.

Apesar de apontar uma série de vantagens do ponto de vista material, profissional, e pessoal, elas estão sempre permeadas pelo conflito e pelo sofrimento. Mas se a vida é tão difícil no Seminário, porque os rapazes permanecem no processo formativo na instituição?

São tantas as dificuldades que se fosse apenas o Seminário a única coisa a me segurar aqui para eu ser padre, já teria saído, não há como ficar. Por que eu fico, apesar de tudo? Sinceramente, não sei. Eu estive com uma dúvida que nunca tive antes. Isso me deixou desconcertado. Pensei em ir embora porque não estava agüentando mais. Resolvi ter calma, superar o sono e o cansaço para rezar. Então a gente vai se reanimando de novo, vai agüentando certas coisas, passa por diversas tribulações... lá na frente, olhamos para trás e vemos tudo o que passamos e nos perguntamos: como foi que passei por tudo isso? Não foi por minhas próprias forças, nem foi o bispo ou padre formador. Foi Cristo. Aí a gente se sente motivado para continuar. A convivência difícil, o ritmo rotineiro do Seminário nos mantêm sempre nos conflitos.
Não sei se é Deus que me segura aqui, porque às vezes me pergunto se realmente ele existe. Mas parece que há uma força maior que me acalma, me faz caminhar com prudência. Uma outra coisa que me segura aqui é a formação acadêmica. Pelo menos temos bons professores. Estou recebendo uma boa formação cultural e isso me anima a permanecer aqui. Eu suspendo os problemas para me dedicar aos estudos. Nossa vida aqui é muito conturbada, mas depois eu penso nos problemas.

Vejo seminarista do terceiro ano que não sabe o que está fazendo aqui. Quando a gente pensa que ele está animado por estar no último ano, na verdade, está cheio de dúvidas se continua no Seminário ou se vai embora, por não agüentar mais essa vida. Vendo o desânimo das pessoas, me pergunto: será que depois de três anos de Seminário eu vou chegar lá desse jeito? Não sei o que vai acontecer. Será que vou terminar a Filosofia? São dúvidas que estão sempre aí. Será que eu vou estar aqui amanhã? Será que meu bispo não vai acordar um dia de mau humor, não vai me mandar embora? Estes problemas estão sempre presentes.

Eu perseverei na esperança de que eu possa fazer diferente um dia. Vendo o que eu acho de errado, espero chegar lá na frente e não fazer isso, não fazer assim. Embora eu tenha medo de me acostumar com isso, acostumar tanto a apanhar e a bater, que lá na frente eu chegue a achar que a vida é isso mesmo. Ficar calejado e não ligar mais. A gente pode ficar com o couro grosso na luta. Mas só não pode ficar com o couro do coração grosso, como diz um amigo meu.

Os seminaristas alegam que permanecem no Seminário por razões de fé, apesar de todos os percalços, insistem 
na sua vocação ao sacerdócio, sem deixar de indicar a importância do fator acadêmico em sua decisão de prosseguir na formação. Uma estratégia utilizada com freqüência pelos seminaristas parece ser a suspensão da questão vocacional um aspecto que concentra os mais variados conflitos - para se dedicarem a ser estudantes de Filosofia, por um certo tempo. Mas no terceiro ano do curso de Filosofia, a decisão vocacional torna-se inadiável. Parece reinar a dúvida e a incerteza nos seminaristas, de um modo crônico. Também se permanece no Seminário por idealismo, para "fazer diferente quando for padre", mas corre-se o risco de sucumbir à luta, ficar insensível, com o "couro grosso".

\section{UMA SINGULAR INSTITUIÇÃO TOTAL}

O Seminário Católico é um estabelecimento que visa à formação de sacerdotes, de padres para a manutenção dos quadros hierárquicos da Igreja Católica. Em seu estatutos e regimentos, este estabelecimento oferece uma formação que se divide em cinco campos: a vida comunitária, a dimensão humano-afetiva, a formação espiritual, a dimensão intelectual e a formação pastoral. Este é o projeto institucional oficial do Seminário.

De acordo com os resultados preliminares obtidos, podemos considerar o Seminário Católico como uma instituição total (Goffman, 1987) dotada de um aparelho ideológico que produz efeitos repressivos e modeladores da subjetividade do seminarista internado. Mesmo considerando sua singularidade, os dados apontaram para as semelhanças entre esse Seminário Católico pesquisado e outros estabelecimentos totalitários, que se impõem de modo persistente e decisivo, obrigando-nos a considerar a especificidade da subjetividade que podem gerar essas formações sociais. Assim, instituições tais como prisões, hospitais psiquiátricos, colégios internos, conventos, seminários para formação de padres e instituições religiosas em geral têm muitos aspectos disciplinares em comum, coisa que não parece tão evidente num primeiro momento.

Pensamos que a estruturação característica desses estabelecimentos totais parece funcionar de modo autônomo e que somente poderemos compreender os problemas sociais e o impacto produzido na subjetividade pelas instituições totais, através do estudo das relações e das práticas sociais subjacentes a esses estabelecimentos.

Estudando esse Seminário Católico, detectamos uma série de procedimentos utilizados pelo estabelecimento na formação dos candidatos ao sacerdócio: a reclusão no claustro do Seminário (aparentemente, o próprio estabelecimento é considerado um instrumento formativo em si mesmo, com monitoração das saídas e ausências); os relatórios de avaliação do processo vocacional de cada seminarista (que acaba sendo visto como um instrumento de controle nas mãos dos formadores); exposições contaminadoras físicas, sociais e psicológicas (os seminaristas permanecem em contato com seus colegas e formadores, expostos a uma observação constante); o circuito (interligação de todas as esferas da vida do seminarista no contexto institucional, monitorando-as e avaliando a "vocação autêntica" do candidato através da sua conduta); a tiranização (que produz uma infantilização social, por exemplo, através da obrigação de pedir permissão); o processo de arregimentação (obrigação de executar a atividade regulada em uníssono com grupos de outros seminaristas; a campainha onipresente); o sistema de autoridade escalonada ( padres formadores, professores, colegas, todos vigiam a todos); o sistema de privilégios (graduação em Filosofia, alto padrão de vida oferecido pelo estabelecimento, que parece produzir um desclassamento e aburguesamento nos seminaristas, os dias livres para saídas do Seminário); uma relação 
de tutela informal e cobertura incompleta das necessidades dos seminaristas (o alívio de responsabilidades econômicas e a exigência de dedicação exclusiva à formação para o sacerdócio); processos de desligamento secretos e sumários de seminaristas do estabelecimento. Esses procedimentos não estão previstos dessa forma nos objetivos oficiais. Eles foram detectados quando olhamos para as práticas cotidianas desenvolvidas no contexto institucional, podemos dizer que eles são o que a instituição não diz, mas faz.

A vida no contexto institucional parece ter sua especificidade, para além ou à revelia dos objetivos oficiais dos formadores. A vida no claustro produz uma série de fenômenos entre os seminaristas, caracterizando o processo de confraternização (problemas de contaminação em que "o inferno são os outros", rivalidades, possibilidades de delação, gozação coletiva, divisão em grupos menores: panelinhas, casais). No seio da comunidade reina o conflito, a "guerra fria", a resistência velada dos seminaristas. Esses fenômenos são notoriamente conhecidos por todos os envolvidos e tacitamente ignorados, são voluntariamente desconhecidos, denegados. Este modo de lidar com o processo de confraternização não deixa de ser enigmático, senão sintomático.

Como os seminaristas reagem às práticas sociais que instrumentalizam sua formação no contexto institucional do Seminário? Quais os efeitos desses procedimentos de modelagem da subjetividade nos seminaristas?

Muitos dos elementos coletados nas visitas de observação participante se confirmaram e os depoimentos dos seminaristas vieram corroborar algumas análises que já havíamos realizado anteriormente. Entendemos que os seminaristas, no seu processo formativo no contexto institucional, estão submetidos a um processo de normatização do seu comportamento. Esse parece ser o eixo estruturante das representações dos seminaristas com relação à sua vida no Seminário. Essa normatização é instrumentalizada através de diferentes estratégias ativadas no processo formativo, conforme já descrevemos a partir dos dados das visitas de observação. A relação entre os próprios seminaristas é caracterizada sobretudo pelo seu aspecto conflitivo: reina uma guerra silenciosa entre eles. A relação entre formadores e formandos também pode ser vista como um campo de luta onde os seminaristas não são passivos, mas oferecem resistência às estratégias normativas que lhes são impingidas, embora evitando um confronto direto.

Os seminaristas costumam sentir o enclaustramento como perda da liberdade; utilizam o quarto individual como refúgio e espaço de privacidade e autonomia pessoal; o alívio parcial e incompleto das necessidades econômicas dentro de uma relação de tutela informal, na qual não se pode trabalhar para obter dinheiro, expõe os seminaristas a situações humilhantes e paradoxais: sentemse pressionados pela gratuidade da sua vida na instituição a responder com bom desempenho nas várias atividades formativas, a cobrança produz neles uma sensação de inferioridade e pouca valia pessoal; o tempo é experimentado como rotineiro, bastante controlado e vigiado; desligamentos misteriosos de colegas produzem ansiedade, pânico, persecutoriedade e sentimento de ser descartável, lançam mão dos ajustamentos secundários, através de ações que mostram sua resistência à modelagem subjetiva e de diversos processos adaptativos (conversão, colonização, sobretudo, a estratégia da "viração" e da dissimulação) para burlar o processo normatizador institucional ao qual estão submetidos. Os seminaristas lidam com a informação de um modo denegatório e a fofoca parece ser o principal indicador desse mecanismo. A vida no contexto institucional pode ser experimentada pelos seminaristas como algo altamente aversivo, experiência 
que não se deseja mais repetir. A percepção da diferença entre o discurso oficial formativo e a prática concreta do aparelho repressivo parece corroer as bases da convivência comunitária, minando a confiança e a segurança dos seminaristas.

Se o objetivo desse Seminário é formar sacerdotes, trabalhando a subjetividade dos seminaristas internados através do processo formativo descrito no Regimento Interno, discurso oficial no qual figuram os objetivos da instituição, estamos constatando que são realmente mais formadoras e modeladoras da subjetividade dos seminaristas internados as práticas sociais que se desenvolvem no contexto institucional. As alterações que realmente ocorrem parecem não ser as desejadas pela equipe dirigente. Os seminaristas parecem submeter-se e deixarse educar, reorganizar-se subjetivamente, mas eles se defendem da "reforma" normatizadora imposta, utilizando-se dos ajustamentos secundários, habituando-se a costumes contrários ao discurso formativo da instituição e também se valendo da estratégia de "dançar conforme a música".

Acreditamos que o processo formativo oferecido pelo estabelecimento Seminário, ao padecer das mazelas estruturais das instituições totais, apesar da sua especificidade e aspectos positivos já apontados, ao funcionar a partir de um dispositivo tipicamente disciplinar, segrega, esquadrinha e submete os seminaristas, que procuram resistir como podem ao processo. Entendemos que os efeitos repressivos desse aparelho institucional impedem que a formação oficialmente buscada seja alcançada.

O processo formativo nesse Seminário Filosófico não faz o que diz, ou se faz, faz de modo sofrível, segundo os seminaristas. Mas pelo contrário, também faz o que não diz, e o faz muito bem. As várias dimensões do processo formativo são implementadas de modo, pelo menos, sofrível, de acordo com os dados, produzindo efeitos e resultados com essa mesma consistência. Já o que se faz sem dizer parece operar com profundidade no processo formativo, implementando uma série de procedimentos "ocultos", "desconhecidos", não intencionais, mas extremamente eficazes. Essa "programação oculta" no funcionamento institucional não pode produzir os resultados que se esperaria dos objetivos oficiais. Desse ponto de vista, esses mecanismos "desconhecidos" produzem o que podem: sujeitos (de)formados, (des)educados na simulação, na hipocrisia, acostumados a rivalidades, delações, vinganças, demonstrando o que não são e escondendo o que realmente são. Aprendem a viver cindidos: "sou assim, mas me mostro do jeito que desejam me ver", "uso a máscara que você quiser" e terminam por denegar a realidade com a qual convivem.

\section{CONCLUSÕES INICIAIS E DIRETRIZES PARA A CONTINUIDADE DO ESTUDO}

O processo formativo no Seminário pesquisado parece tentar normatizar os comportamentos, pensamentos e sentimentos dos seminaristas. A relação formativa entre a equipe dirigente e os seminaristas internados apresenta-se plena de contradições. Por um lado, há um discurso que proclama a participação, a iniciativa, a "liberdade com responsabilidade", conjugadas com um chamado para que o seminarista assuma a tarefa formativa como uma responsabilidade pessoal no estabelecimento. Ao mesmo tempo, o seminarista sente-se pressionado a conformar-se com as normas, deve aderir e formar consenso ao redor do projeto eclesiástico proposto pela organização.

Detectamos o funcionamento de controles autoritários, explícitos e implícitos no contexto institucional, além do controle exercido pelos pares. O ideal visado parece ser a internalização do controle: 0 autocontrole.

Acreditamos que o modo de funcionamento desse Seminário Católico, as 
práticas sociais desenvolvidas, para além do discurso formativo de caráter participativo, numa política contraditória, podem estar produzindo nos seminaristas internados comportamentos bastante próximos do perverso. Os seminaristas colocam-se no papel de vítimas impotentes diante de um aparelho repressivo, lançando mão do uso de mecanismos de defesa tipicamente perversos: a clivagem (coexistência no ego de duas atitudes diversas para com a realidade, ambas persistem e não se influenciam) e a recusa (não reconhecimento de uma realidade de percepção traumatizante). Aparentemente, as contradições internas no processo formativo deste Seminário Católico estudado estariam produzindo seminaristas com uma subjetividade caracterizada pelo cinismo, astúcia, agressividade e ambição.

Esse Seminário Católico, por seu irrevogável caráter de instituição total, parece deixar muito remotas as ações instituintes, tanto pela desvalorização como pela coerção de ações coletivas de contra-hegemonia. Nessas condições, parecem possíveis ações individuais ou coletivas fundadas ou na renegação clandestina da ordem ou nas ocorrências do ato perverso ou mesmo psicopático - fazer clandestinamente ações contra as normas da ordem institucional sustentando, ao mesmo tempo, a afirmação do respeito a ela.

Os seminaristas expressam, em geral, com tons bastante agonísticos, os modos como repercutem neles as práticas institucionais desse Seminário e, sobretudo, a contradição observada nestas com um certo imaginário do Seminário como espécie de microparaíso e com o próprio discurso institucional oficial. Isso volta ou se manifesta em angústia, crítica e autocrítica, rancor, revolta velada e, às vezes, declarada; somatizações e escotomização (percebo, mas esquecerei).

A partir do estágio atual de nossas análises, emerge a hipótese de que os seminaristas parecem viver um tempo e circunstâncias que devem, a priori, ser varridos da sua história, algo que, embora seja condição inevitável para sua ordenação sacerdotal, é ao mesmo tempo algo que se suporta fundado na certeza de que será esquecido. Constatamos nos seminaristas entrevistados que a experiência desse tempo de formação vivido nesse Seminário coexiste com a esperança redentora do recalque.

Pensamos que esta pesquisa pode ser ampliada e desenvolvida a partir da contribuição de Foucault (1984, 1999a, 1999b): o Seminário pode ser investigado como um estabelecimento que encarna o poder disciplinar e as instituições disciplinares que esse poder implementa, procurando detectar como são os sujeitos que seu funcionamento microfísico produz, focalizando as relações de formação entre formadores e seminaristas como um dispositivo privilegiado de constituição do Seminário enquanto agência de produção de subjetividade. À luz das contribuições de Foucault, nossos dados podem revelar as características e nuances do Seminário, permitindo compreendê-lo como dispositivo organizado de modelagem subjetiva, tanto por seus discursos e por suas práticas, quanto pela articulação (sintonia ou contradição) desses dois aspectos. Ao mesmo tempo, podemos aspirar a compreender com maior desenvoltura as características da subjetividade aí produzida e suas possíveis implicações para a performance social dos padres como sujeitos emergentes desse processo institucional.

\section{REFERÊNCIAS BIBILIOGRÁFICAS}

ALBUQUERQUE, J. A. G. (1980) Instituição e poder: a análise concreta das relações de poder nas instituições. Rio de Janeiro: Graal.

ALVES-MAZZOTTI,A.J\&GEWANDSZNAJDER, F. (1999) O método nas ciências naturais e sociais: pesquisa quantitativa e qualitativa. $2^{\mathrm{a}}$ ed. São Paulo: Pioneira. 206 p. 
BLEGER, J. (1980) Temas de psicologia: entrevista e grupos. São Paulo: Martins Fontes, $113 \mathrm{p}$.

CASTEL, R. (1978) A ordem psiquiátrica: a idade de ouro do alienismo. (Albuquerque, M. T. C., Trad.) Rio de Janeiro: Graal, 329 p.

FERRAZ E FERRAZ, M.G.C. (1994) Religare. Uma cartografia da fé. Tese de doutorado. Pontifícia Universidade Católica de São Paulo. São Paulo, SP. Vol. 1, 128 p.

FOUCAULT, M. (1984) A verdade e as formas jurídicas. "Cadernos da PUC/RJ, série Letras e Artes", 6/74, nº 16.

(1999a) História da Loucura na Idade Clássica. $6^{a}$ edição. São Paulo: Perspectiva. (Original publicado em 1972). 551 p.

, (1999b) Vigiar e punir: nascimento da prisão. 21 a . ed. (Ramalhete, R., Trad.). Petrópolis: Vozes. 288 p. (Original publicado em 1975).

GUIRADO, M. Instituição e relações afetivas: o vínculo com o abandono. São Paulo: Summus, 1986. 213 p.
Psicologia institucional. São

Paulo: EPU, 1987.

GOFFMAN, E. (1975) Estigma: notas sobre a gestão da identidade deteriorada.(Leite Nunes, M. B. M., Trad.) RJ: Zahar. 158 p. , (1987) Manicômios, prisões e conventos. (Leite, D. M., Trad.) $2^{\mathrm{a}}$ ed. São Paulo: Perspectiva. 319 p. (Original publicado em 1961).

LEFÉVRE, F. et.al. (2000) O discurso do sujeito coletivo: uma nova abordagem metodológica em pesquisa qualitativa. Caxias do Sul: EDUSC, 2000. 138 p.

LEVINSON, D. J. \& GALLAGHER, E. B. (1971) Sociología del enfermo mental. Buenos Aires: Amorrortu. 283 p. (Original publicado em 1964).

TRIVIÑOS, A. N. S. Introdução à pesquisa em ciências sociais: a pesquisa qualitativa em educação. São Paulo: Atlas, 1987. 